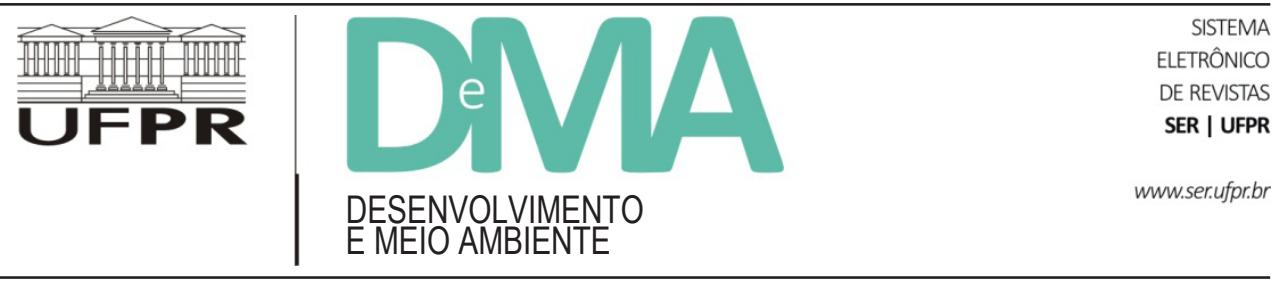

\title{
Extrativismo em Moçambique: construindo outros diálogos
}

\section{Extractivism in Mozambique: Building Other Debates}

\author{
Edgar Manuel BERNARDO ${ }^{1 *}$, Alexandre Silva DUNDURO², Lucas Alberto NERUA ${ }^{1}$, Gudo Bai Armando \\ MAIDJELELE ${ }^{1}$ \\ ${ }^{1}$ Universidade Federal do Ceará (UFC), Fortaleza, CE, Brasil. \\ ${ }^{2}$ Instituto Superior de Relações Internacionais (ISRI), Maputo, Moçambique. \\ *E-mail de contato: ebernardo90@gmail.com
}

Artigo recebido em 11 de outubro de 2015, versão final aceita em 15 de agosto de 2016.

RESUMO: O texto apresenta uma proposta ampla de debate sobre os contornos e dinâmicas da exploração dos bens naturais em Moçambique. O desenvolvimento do debate aqui proposto apresenta-se de forma crítica relativamente ao modelo de desenvolvimento aderido pelo país que, à semelhança dos vários países do mundo, configura-se como um modelo extrativista e lucrativista de desenvolvimento com traços essencialmente capitalistas. Faz-se crítica das posições acadêmicas e políticas no país, que não se propõem a transpor as barreiras dos conceitos convencionais de desenvolvimento e exploração dos bens naturais, não demonstrando, desse modo, quaisquer sinais de ruptura e questionamento a esses modelos. No artigo, debateremos caminhos e propostas para novas ações em torno da exploração dos bens, considerando várias experiências mundiais, em particular de países da América Latina. Esses debates encerram-se em variáveis que o PIB não pode captar, no caso de questões ecológicas, por exemplo.

Palavras-chave: bens naturais; desenvolvimento; redistribuição da riqueza; autodeterminação dos povos.

ABSTRACT: This text presents a comprehensive proposal to debate the contours and dynamics of natural resources exploitation in Mozambique. The development of the debate proposed here presents a critique for the development of Mozambique, by various countries of the world, as an extractive and lucrative development model with essentially capitalist traits. It criticizes academic and political positions in the country which do not try to overcome the barriers of conventional development concepts and exploitation of natural resources, thus not demonstrating any signs of disruptions and questioning of this model. In the article, we will discuss ways and proposals for further action in the holding of assets, considering various global experiences, particularly from Latin America. These discussions contain within them variables that GDP could not capture, such as ecological issues.

Keywords: natural goods; development; wealth redistribution; self-determination of peoples. 


\section{Introdução}

Existe uma tendência de relocalização das indústrias extrativas em nível mundial. Vários motivos podem ser assinalados para esse fenômeno. O primeiro deles já havia sido verificado por Marx (2014), que é a ontológica necessidade do capitalismo se expandir em busca de novos mercados. Um capital localizado condena-se à estagnação e à extinção. A mundialização é sempre necessária para a reprodução do capital. Para além deste elemento intrínseco e necessário para o capitalismo, os países do Norte Global atravessam crises que, no presente século, se agudizaram a partir de 2008, como resultado do modelo de acumulação vigente (Harvey, 2014). Diante dessas situações, tornou-se cada vez mais necessário um "retorno" ao Sul sob a forma de agronegócio e da extração mineral para a produção de commodities. No caso do Brasil, como assinalou Prado Jr. (2011, p. 23):

Se vamos à essência da nossa formação, veremos que na realidade nos constituímos para fornecer açúcar, tabaco, alguns outros gêneros; mais tarde, ouro e diamante; depois algodão, e em seguida café, para o comércio europeu. Nada mais que isso. É com tal objetivo, objetivo exterior, voltado para fora do país e sem atenção a considerações, que não fosse o interesse daquele comércio, que se organizarão a sociedade e a economia brasileira. Tudo se disporá naquele sentido: a estrutura social, bem como as atividades do país. Virá o branco para especular, realizar um negócio; inverterá seus cabedais e recrutará a mão de obra de que precisa: indígenas ou negros importados.

Para além da América Latina, em particular o Brasil, o continente africano é um dos pontos que atraem os grandes investimentos. Rigotto (2008), ao olhar para este cenário, concebe diferentes motivações para a sua decorrência, entre os quais a fuga das exigências de um novo urbanismo e da reforma ecológica em curso em alguns países centrais, para ir ao encontro de vantagens competitivas como solo barato, incentivos fiscais, mão de obra barata e dócil, e sociedades mais frágeis em sua organização.

Moçambique é um dos atuais receptores dos grandes projetos de investimento. A descoberta dos bens naturais ou do boom dos "recursos naturais", ensaiado no limiar da primeira década do presente século no país, afirmam-se como um dos principais episódios de sucesso depois de dois sucessivos eventos (amargos) ao longo dos últimos quarenta anos, nomeadamente, a guerra de libertação nacional e a guerra civil. Assim, não são estranhos a euforia e o desejo dos políticos e outros atores sociais em abrir uma página diferente e traçar um novo percurso na história.

Ao abrir-se essa nova página, o desenvolvimento tornou-se palavra de ordem; o Investimento Direto Estrangeiro (IDE), independentemente de onde venha, tornou-se indispensável, o Produto Interno Bruto (PIB) passou a guiar todo o debate sobre o futuro "promissor" de Moçambique. Infelizmente, o eterno desejo de bem-estar nacional foi deglutido pela quantificação dos avanços que o governo estabeleceu como prioritários. Os diferentes grupos sociais, o cuidado com a natureza, a preservação dos recursos hídricos, o meio ambiente, todos foram relegados para um plano secundário quando o país, finalmente, inaugurou-se na exploração dos bens da natureza. E como diz Rigotto (2008, p. 23):

\footnotetext{
Nos novos territórios escolhidos para sua relocalização, estas indústrias são anunciadas e saudadas como o advento do progresso, e ali, frequentemente, recebidas de braços abertos seja pelos governos, seja pela maioria da população. A perspectiva da criação de empregos e de geração de renda, em contextos sociais vulnerabilizados pela pobreza e pela penúria historicamente construídas, é muitas vezes um apelo incontestável e inquestionável.
} 
O ponto central é que essa descoberta e exploração dos bens, liderada pelas grandes empresas transnacionais capitalistas, obedece, de forma geral, a uma lógica internacional de relocalização dos projetos extrativistas, sendo os países tidos como não desenvolvidos os potenciais destinos das mesmas, independentemente dos possíveis danos.

\section{Relação ciência e natureza}

Dentro do paradigma da ciência moderna e hegemônica, os recursos naturais ou a terra, no seu todo, constituem meios de dominação e apropriação, vista, assim, como o caminho irrefutável para a realização do bem-estar humano. Conforme Bacon, a ciência fará da pessoa humana "o senhor e o possuidor da natureza" (apud Santos, 2010b, p. 25).

O desenvolvimento da ciência e da técnica serviu para a realização dos desejos do homem de dominar e continua sendo um domínio sem limites. Domínio sobre a terra, sobre o subsolo, sobre as águas e até sobre os outros planetas. Pois, "de acordo com esse modelo de ciência, o homem, como senhor do mundo, pode transformar a natureza, explorá-la, fazer com que essa seja sua serva, escrava, mantendo apenas o direito de obediência às ambições do ser humano" (Moraes, 1999, p. 33).

É inegável que o avanço da ciência, do conhecimento, levou a humanidade a horizontes e patamares um dia inimagináveis. Ela foi e é elucidativa, enriquecedora, conquistadora e triunfante (Morin, 2013). Com ela, a humanidade teve grandes avanços, porém, essa mesma ciência que conquista, enriquece e triunfa, apresenta também muitos problemas no que se refere ao conhecimento que produz a ação que determina e à sociedade que transforma (Morin, 2013). Segundo Moraes
(1999), a ciência levou-nos a uma concepção da vida em sociedade como uma luta competitiva pela existência, crença no progresso material ilimitado a ser alcançado por meio do crescimento econômico e tecnológico.

Estamos no séc. XXI, mas em termos científicos e de produção da ciência, nos vemos ainda imersos na era moderna, em que as nações ainda não estão conscientes da necessidade de alternativas em relação às concepções e formas de produção científica, assim como da satisfação das necessidades humanas. Por esta razão, quando se pensa no paradigma do desenvolvimento, pensa-se antes de tudo nos números. A vida de um país é muitas vezes avaliada pelo indicador macroeconômico, o PIB. A quantificação é a grande herança do paradigma da modernidade. Só são úteis os números e o que é quantificável. A sociedade se encontra em constante e grave estágio de monetarização. Vivemos numa sociedade mercantilista. Uma sociedade em que tudo se compra e tudo se pode vender (Bauman, 2008).

O capitalismo conseguiu fazer da sua produção e das necessidades valores fundamentais para a existência humana. Ele tornou-se "religião", como se referiu Benjamin (2013). Toda religião precisa ser cultuada e possui elementos simbólicos materiais e imateriais que servem de guia orientador. Com o capitalismo, no campo imaterial, verifica-se a produção de desejos. Vivemos numa verdadeira sociedade de desejos. Independentemente do status social que os indivíduos detêm, das possibilidades de satisfação, o desejo está sempre presente. É o desejo do consumo, este é o elemento material da religião capitalista.

Na perspectiva da Moraes (1999), a produção econômica tem sido a preocupação central da sociedade e o crescimento econômico passou a ser a principal medida pela qual as sociedades julgam seu progresso. Avalia-se o produto pelo quantitativo, ao mesmo tempo em que se ocultam as desigualdades 
sociais e ambientais produzidas, já que os números não mostram como se distribuem os bônus e os ônus deste modelo de desenvolvimento entre as diferentes classes e segmentos sociais. Há, portanto, uma crença na necessidade de um crescimento contínuo, desmesurado, a qualquer preço, decorrente de uma excessiva ênfase nos valores de expansão, autoafirmação e competição.

É por isso que urge questionarmo-nos sobre as consequências desse modelo de racionalidade. É também tarefa de todos nós o questionamento dos paradigmas da ciência moderna que têm servido de base de orientação para construção e solidificação de saberes, seja no Norte ou no Sul global. E para os que já deram um "salto" em direção ao Sul, é fundamental que se aprofunde o campo epistêmico para a consolidação dessa perspectiva, de forma que se coloquem em visibilidade todos os saberes historicamente silenciados em nome do saber hegemônico científico ocidental. Para que não se caia no novo simplismo e reducionismo, faz-se necessário pensar em como colocar as duas epistemologias (Norte e Sul) em diálogo, pois existem respostas que uma tem e que a outra não dispõe e vice-versa (Santos, 2010b).

\section{Do debate sobre a exploração dos bens naturais em Moçambique}

A tradição científica da modernidade exerce enorme influência nos pressupostos éticos, políticos e epistêmicos que até então são usados para os debates no mundo e, em particular, em Moçambique. Quando o que está em causa são os bens naturais, os discursos mais corriqueiros, seja de acadêmicos ou políticos da "esquerda" ou mesmo da "direita", direcionam-se para a lógica de exploração e redistribuição da riqueza gerada. O que se ouve é a crítica dos acadêmicos em relação aos benefícios coletivos da exploração desses bens, sem jamais questionar-se o paradigma desenvolvimentista por via extrativista.

Os elementos negativos do processo extrativista são invisibilizados pelos discursos hegemônicos, principalmente pela aposta na evidenciação dos ganhos econômicos. Hofmann e Martins (2012) são elucidativos quanto a esse ponto. No texto intitulado Descoberta dos recursos naturais em Moçambique: riqueza para poucos ou um meio de sair da pobre$z a$ ?, os autores fincam-se no debate essencialmente desenvolvimentista, ao afirmarem que "a maneira de lidar com esses recursos caracterizará o futuro desenvolvimento de Moçambique", seguido da ideia da redistribuição que abordamos anteriormente. Para Hoffman \& Martins (2012), Moçambique precisa combater o paradoxo da riqueza mediante a criação de instituições para o controle e a distribuição de riquezas provenientes de matérias-primas. Quando se pensa na redistribuição da riqueza, têm sido indicadas três vias: a geração de impostos, a geração de empregos e a redução da pobreza. A primeira tem como ideia basilar que os mesmos podem ser investidos em políticas sociais, porém, essa perspectiva enfrenta enormes paradoxos, como é o caso das isenções fiscais e tributárias exigidas pelos investidores, que reduzem os retornos aos cofres do Estado; dos financiamentos públicos diretos aos empreendimentos; das obras de infraestrutura necessárias aos empreendimentos (estradas, linhas de energia elétrica, portos, aeroportos), que são comumente realizadas pelos Estados e com recursos públicos; da subordinação da política de ciência e tecnologia e de formação de pessoas às demandas de conhecimento científico e técnico dos empreendedores, sempre com recursos públicos.

A Vale S.A. beneficia-se de $15 \%$ de desconto no imposto sobre o rendimento de pessoas colectivas (IRPC), que recai sobre a mina durante os 
primeiros 10 anos (de 2011 a 2021), redução em $5 \%$ para a central de energia térmica que também faz parte do projeto e facilidades para aquisição de imóveis (Mosca \& Selemane, 2011). Ainda fazem parte dos benefícios concedidos à Vale o livre repatriamento de lucros e dividendos até $100 \%$ (Castel-Branco \& Cavadias, 2009) e o pagamento da ínfima quantia de 3\% sobre o rendimento líquido trimestral da mina (Mosca \& Selemane, 2011). De acordo com Castel-Branco (2013, p. 4):

A Vale, a SASOL, a Kenmare, a BHP Bilington, a Anadarko, a Artumas, etc., geram bilhões de dólares a cada ano para as suas estratégias mundiais. Cada uma destas empresas tem um lucro líquido anual muitas vezes maior do que o orçamento anual de Moçambique. Para eles, Moçambique é uma fonte de recursos e lucros. Isto é o que podemos racionalmente esperar de uma empresa multinacional sob o capitalismo mundial.

Esses dados são indicativos de que os projetos extrativistas não estão direcionados para o mercado interno, mas sim para o mercado internacional. Sendo as atividades realizadas no país meramente extrativas, há uma impossibilidade de gerar valores que pudessem dar sustento às teses da geração de renda. Isto nos possibilita aventar que "o país apenas serve de um espaço onde são expulsos os detentores da terra e colocados na miséria; são destruídas várias áreas que se tornariam áreas de prática de agricultura de subsistência e da criação de animais [...]"' (Matos \& Medeiros, 2013, p. 253).

Outra ideia bastante propagada está relacionada à geração de empregos. Nesse ponto, podem ser questionados os números de empregos gerados, para que classes sociais, o nível de remuneração oferecido, a qualidade de emprego se comparada às atividades e ocupações tradicionalmente exercidas pela população, a precariedade das relações e condi- ções de trabalho, a tendência à desregulamentação sobre os direitos dos trabalhadores.

É fundamental perceber-se que a compreensão de desenvolvimento não conseguiu, até então, dissociar-se da ideia de crescimento. Trata-se de um crescimento desenvolvimentista, que tenta aliar os números com o bem-estar humano num difícil exercício aritmético.

Pode-se encontrar, ainda, essa visão puramente economicista ganhando eco em algumas das mais cotadas publicações em Moçambique. Referimo-nos ao Centro de Integridade Pública (CIP). Selemane (2009), um dos proeminentes pesquisadores da instituição, na sua publicação Alguns desafios na indústria extrativa em Moçambique, direciona o debate em torno dos "ganhos ou perdas" por via da exploração dos recursos naturais. Nos seus capítulos introdutórios, elabora-se o seguinte questionamento: "Sendo um novo-rico em hidrocarbonetos, será que Moçambique vai experimentar também o sabor amargo da maldição, ou conseguirá obter a almejada bênção para a redução da pobreza?" E prossegue o estudo com mais uma questão que espelha profundamente a quantificação do debate sobre os recursos naturais no país: "Até que ponto a atual exploração contribui para a riqueza do país?”.

Um dos problemas, dos vários que essa perspectiva de abordagem economicista pode trazer, é que o cidadão reorienta as suas necessidades e ambições em função dos índices dos ganhos com a exploração e a exportação dos recursos naturais, o que pode ser bastante ilusório e frustrante, pois os próprios acadêmicos e políticos, ainda na vertente de ganhos e perdas, acreditam que a nação poderá beneficiar-se dos eventuais ganhos num horizonte temporal de trinta a cinquenta anos, o que sugere que os cidadãos deverão esperar pacientemente, durante um período de tempo indeterminado, para atingir o almejado bem-estar. 
Mosca \& Selemane (2011), com o texto intitulado El dorado Tete, apesar da "doxa" no contexto moçambicano, conseguiram levar adiante um debate diferente, problematizando a essência dos grandes investimentos no setor extrativo-mineiro na província de Tete. Esses autores afirmam, na contextualização do seu debate, que os megaprojetos beneficiam-se de incentivos fiscais, de excepcionalidades legais e de facilidades de operação que nenhuma das outras entidades econômicas gozam. Os autores delimitam como discussão central de sua obra a preocupação em perceber os efeitos dos megaprojetos de mineração nas cidades de Tete e Moatize $^{2}$, com especial atenção para os principais setores econômicos locais, os fenômenos migratórios e o mercado de trabalho, a questão da infraestrutura, a inflação local, a problemática dos reassentamentos e a governança, que é, sem dúvida, uma das consequências imediatas nesse processo e que as regiões afetadas por esses projetos já vivenciam.

Castel-Branco, um dos mais destacados intervenientes no debate sobre os recursos naturais em Moçambique, no seu estudo "Refletindo sobre acumulação, porosidade e industrialização no contexto de economia extrativa" (2013 3 ), a priori, distancia-se da perspectiva economicista do debate. $\mathrm{O}$ autor começa por reconhecer que "o debate sobre recursos naturais na economia de Moçambique é amplo, abrangente e intenso" (Castel-Branco, 2013, p. 81). E, mais adiante, de uma forma bastante lúcida o autor $(2013$, p. 81$)$ refere que:

O número e a qualidade de seminários, conferências, blogs, artigos e intervenções em fóruns acadêmicos, sociais, empresariais e políticos aumenta, e os temas variam entre a apropriação de rendas (por via de impostos, quotas de fornecedores ou o acesso à estrutura acionista das empresas) e meio ambiente, passando pela geração de emprego, reassentamento dos cidadãos expropriados, responsabilidade social corporativa, volatilidade macroeconómica, transparência, financiamento dos serviços públicos, entre outros.

No entanto, esse reconhecimento de um amplo e importante debate, sob diversas perspectivas no que se refere aos bens naturais que o autor faz menção, não passa de um mero reconhecimento, aliás, é apenas uma menção fugaz, pois as suas discussões centram-se na vertente econômica.

Nessa abordagem, o que fica subjacente é que, embora se reconheça o impacto nefasto da exploração dos bens naturais para o ambiente, por mais que os cidadãos sejam obrigados a abandonar as suas zonas de origem, abdicando de todas as suas práticas socioculturais, religiosas e dos seus meios de sobrevivência, bastará que o governo adote mecanismos para uma justa redistribuição de riqueza e tudo ficará resolvido. Além de não ser realístico, esse discurso, vindo de acadêmicos, representa nada mais que um pacto latente com a ideologia das grandes empresas capitalistas, assim como dos Estados parceiros.

A visão da elite política nacional, do governo e, curiosamente, dos partidos políticos militando na oposição, não parece diferente das perspectivas acadêmicas. $\mathrm{O}$ que acaba sendo indicativo de que as linhas ideológicas do governo e da oposição não se diferenciam. Um exemplo elucidativo é a pouca importância que se dá ao perfil das empresas

\footnotetext{
${ }^{1}$ Crença ou opinião comum dos intelectuais moçambicanos com relação aos benefícios do extrativismo em Moçambique.

${ }^{2}$ Moatize é distrito da Província de Tete em Moçambique.

${ }^{3}$ Carlos Nuno Castel-Branco. In: Brito, L. D. et al. Desafios para Moçambique (2013).
} 
com as quais o governo assina os contratos para a exploração dos recursos naturais. Não parece haver preocupação com questões relevantes, tais como: os antecedentes da empresa no tocante aos crimes contra o ambiente, a relação com as comunidades onde essas empresas já se encontram instaladas, a relação com os trabalhadores, os impactos das suas atividades na saúde da população, recursos hídricos e toda a biodiversidade.

O discurso sustentado pelo governo espelha a visão economicista na relação entre a exploração dos recursos naturais e o alcance da riqueza como se ela fosse direta e objetiva. No seu discurso à nação, no ano de 2004, o então presidente da República, Armando Guebuza, que foi o maior incentivador desses projetos, afirmou: "Nós temos de ter a certeza que somos capazes de deixar de ser pobres. Podemos, merecemos e somos capazes de ser ricos. Temos de cultivar a autoestima. Os recursos são todos $\operatorname{nossos}^{4}[\ldots]$ '.

É interessante notar que esse enfoque sobre a riqueza é feito relacionando intrinsecamente o ser rico e a existência de bens naturais, o que deixa transparecer que todos os outros fatores, tais como a disponibilidade para trabalhar, a qualificação técnica dos cidadãos, o acesso à educação, entre outros, são aspectos secundários nessa acesa luta na busca da riqueza. Não é por acaso que na ótica do governo é preciso que os moçambicanos tenham paciência para que possam sentir os reais efeitos da exploração dos recursos naturais. Em outras palavras, quer dizer: "Deixemos que o PIB guie as ambições da nação”. Cabe questionar sobre o lugar em que o patrimônio cultural destes povos e suas tradições são colocados, suas histórias e suas lutas.

\section{4. $O$ avesso da bonança}

Enquanto os possíveis ganhos dos grandes projetos de investimentos são anunciados a longo prazo, as perdas não tardam a se manifestar. Com a entrada dos projetos extrativistas, notam-se enormes processos de vulnerabilização da população residente nas regiões onde os projetos são instalados, a começar pela perda de suas terras e territórios que, para além de serem significativas do ponto de vista material, o são também do ponto de vista simbólico; a perda da água e outros bens comuns, a desestruturação das formas locais de produção e a satisfação das necessidades básicas, transformação cultural, contaminação das águas, do solo, trabalho precarizado e outros malefícios da bênção amaldiçoada do extrativismo.

Para o caso da mineradora brasileira Vale S.A., por exemplo, que está desenvolvendo a mineração a céu aberto na província de Tete, os danos ambientais são imensuráveis, para além de que "requer um uso desmesurado de recursos, tais como água e energia, ela produz visíveis e profundas mudanças na paisagem e nos territórios. Para retirar os minerais, se remove uma grande quantidade de rochas mediante o uso de toneladas de explosivos" (Scotto, 2014, p. 40). Scotto (2014) acrescenta ainda que a água contaminada com cianeto e metais pesados se deposita em piscinões, que costumam romper-se, deixando seu conteúdo contaminado fluir em direção a rios, córregos e lençóis freáticos.

Ressalta-se que a instalação da Vale S.A. implicou a deslocação forçada de pessoas que desenvolviam diversas práticas nos seus territórios, dentre as quais, as atividades pecuárias e agrícolas (Bernardo, 2016). Entre 9 de novembro de 2009

${ }^{4}$ Jornal Domingo: 28 de Novembro de 2004, citado por Chichava, 2009; p. 10. 
a 28 de abril de 2010, foram deslocadas 1.313 famílias, o que corresponde a mais de 5 mil pessoas (Selemane, 2010; Mosca \& Selemane, 2011). As mesmas residiam em cinco comunidades diferentes: Chipanga, Bagamoyo, Chithata, Malabwe e Mithethe (Selemane, 2010) e foram reassentadas em dois locais distintos, Cateme, a $40 \mathrm{~km}$ de Tete, e bairro 25 de Setembro, na vila de Moatize. A divisão da população para os dois destinos baseou-se na classificação em rural (717 famílias) e urbana (596), mediante um censo realizado pela própria Vale (Ramos, apud Mosca \& Selemane, 2011; Matos \& Medeiros, 2013; Bila, 2014; Bernardo, 2016). Atualmente, essas comunidades vivem diante de diversas privações, entre as quais privação da água, saneamento básico, terras férteis para a agricultura e pastorícia, comprometendo-se, desta forma, a soberania alimentar das mesmas (Mosca \& Selemane, 2011; Bila, 2014; Bernardo, 2016).

O relatório de insustentabilidade da Vale (2015), realizado por pesquisadores avessos às políticas da empresa, afirma que esta empresa diz ter comprometimento com a geração de um legado positivo para as comunidades, mas na verdade o que se vê é a intensificação da exploração e degradação crescente dos territórios e da vida das pessoas. Para o caso de Moçambique, os ônus apresentados pelo relatório estão relacionados com a poluição atmosférica devido à exploração do carvão a céu aberto e os reassentamentos em condições precárias para cerca de 1.313 famílias, conforme havíamos assinalado. Isto, inevitavelmente, causou e continua causando a desestruturação das relações sociais, organizações comunais e modos de vida tradicionais dessas comunidades. E como foi referido por Porto et al. (2014, p. 4074):

Dinâmicas territoriais homogeneizadoras formam um território-mundo que impõe, sob uma lógica mercantil, novos tempos e racionalidades que desconsideram as especificidades do território, incluindo seus ecossistemas, povos, cosmovisões e cultura. Todos esses processos interagem de forma complexa e produzem injustiças ambientais, entendidas aqui como mecanismos pelos quais sociedades desiguais destinam a maior carga dos danos ambientais do desenvolvimento as populações marginalizadas e vulnerabilizadas.

A nocividade da mineração em termos socioambientais tem sido registrada. Gonçalves e Mendonça (2007) realizaram um estudo que visava compreender os impactos socioambientais da produção de carvão em Criciúma, Santa Catarina. A constatação feita pelos autores foi de elevados custos sociais e ambientais, principalmente no que tange à poluição do sistema hídrico, para além da poluição do ar, da degradação do solo, vegetação e fauna, o que afetou em grandes proporções as comunidades ao entorno. Dentre várias privações, estas comunidades vivenciaram privação da água, pois a de uso da população tornou-se ácida e existiam altas concentrações de metais dissolvidos nela.

No contexto moçambicano, Bila (2014) é quem oferece algumas informações de danos ao meio ambiente. Segundo os moradores da região de N'chenga, que é uma das atingidas, a Vale lava o carvão extraído nas águas do rio Nyacamuanzi, que serve à comunidade local, causando poluição nas águas, bem como no lençol freático. Este fato teve como implicação imediata o encerramento dos quatro poços de água usados para o consumo da comunidade, bem como a morte de gados bovino e caprino (Bila, 2014), fundamentais para a alimentação dessas comunidades, assim como para o comércio. Estes acontecimentos são reveladores de descomprometimento com pelo menos dois direitos fundamentais, o direito à água e ao alimento, o que consequentemente pode nos levar a uma terceira negação dos direitos, o direito à vida. 
Esses direitos não estão dissociados. Em geral, "o discurso sobre o direito à vida pressupõe sempre e está intimamente relacionado com o direito à alimentação" (Ramose, 2010, p. 199). Esse direito é tão básico que Donnelly (1985, p. 13) chega a afirmar que "a primeira e fundamental manifestação egoísta que cada indivíduo pode fazer contra a humanidade, sem qualquer constrangimento moral, é a afirmação do direito à alimentação" (apud Ramose, 2010, p. 199). Trata-se de um direito básico que dá sentido à existência humana. Mediante essas considerações, podemos, então, aludir que da forma como o projeto da Vale está afetando a soberania alimentar das comunidades, constitui uma gravíssima violação dos direitos humanos das comunidades e que a acumulação por espoliação constitui uma sequência de negação dos direitos humanos.

No geral, podemos afirmar que, pela forma de atuação dos projetos anunciados como sendo de desenvolvimento, percebemos que, pelo menos do ponto de vista das comunidades onde essas empresas encontram-se instaladas, o desenvolvimento está sendo às avessas. Mosca \& Selemane (2011) falam do elevado custo de casas, de transporte, de alimentação, fluxos migratórios, jamais vistos em situações anteriores. Esses problemas estão, de certa forma, relacionados com o que a literatura denomina de maldição dos recursos. Santos (2012), ao analisar o contexto moçambicano, concebe que a maldição está sendo e pode ser notável pelo crescimento do PIB ao invés do desenvolvimento social; a corrupção generalizada da classe política, que defende seus interesses privados por tornar-se cada vez mais autoritária como forma de se manter no poder, agora visto como forma de acumulação prioritária; o aumento, em vez de redução da pobreza; a crescente polarização entre uma pequena minoria rica e uma maioria de mendigos; a destruição ambiental e sacrifícios incontornáveis da população em áreas onde os recursos se encontram, em nome de um progresso que eles próprios nunca conhecerão; a adoção de uma cultura de consumo que está disponível apenas para uma pequena minoria urbana, mas imposta como ideologia em toda a sociedade; a supressão do pensamento crítico e ações de protesto da sociedade civil sob a justificativa de que esta representa obstáculos ao desenvolvimento e age como profeta da desgraça. Em resumo, os riscos são de que, depois deste ciclo de orgias de recursos, o país encontre-se econômica, social, política e culturalmente mais pobre do que era no início (Santos, 2012).

\section{Por outras vias}

Almejar o desenvolvimento para todos nos moldes capitalistas constitui uma ilusão. O desenvolvimento já não é o ideal a ser seguido. Precisamos de alternativas para o desenvolvimento, o que é diferente de desenvolvimento alternativo. A alternativa para o desenvolvimento deve ter como uma das bases fundamentais a crítica ao economicismo e lutar pela autorrealização coletiva. Boaventura de Sousa Santos $(1995 ; 2007)$ é um dos teóricos que busca por alternativas para o desenvolvimento e sugere que a sociedade global almeje a autodeterminação dos povos. Pois é impossível conceber o desenvolvimento sem o crescimento econômico e este, sem apropriação, exploração e danificação da natureza, seus recursos e imensas consequências humanas.

Falar da autodeterminação dos povos ao invés de desenvolvimento é manifestação de desejo a vida digna que não se resume à mercantilização. Pois reduzir a vida dos indivíduos a números ou a variáveis econômicas é ignorar a complexidade que rodeia os indivíduos. Essa complexidade é consti- 
tuída pelo econômico, o político, o sociológico, o psicológico, o afetivo, o mitológico, o ambiental, o territorial, como referiu Morin (2008).

Contudo, o que notamos no contexto moçambicano é a hegemonia de um debate meramente economicista, que ofusca a complexidade da vida humana. Destarte, vemo-nos diante de inteligências incapazes de perceber a complexidade existente, podendo resultar na cegueira e na irresponsabilidade na condução dos destinos do país, o que faz urgente a necessidade de uma visão pluridimensional na análise do impacto do extrativismo em Moçambique, para que não sejamos reféns da perspectiva economicista, na qual a vida humana reduz-se a ganhos econômicos.

Por estas razões, consideramos fundamental o estabelecimento de outros diálogos no debate sobre os investimentos extrativistas em Moçambique. Esses diálogos variam desde o impacto da espoliação das terras das comunidades locais, dos impactos ambientais resultantes da exploração dos bens em diferentes lugares, da saúde dos trabalhadores dos locais onde essas empresas estão funcionando e da população no seu todo, a precarização do trabalho, a poluição das águas, a destruição dos artefatos materiais e simbólicos dos povos nativos e outros elementos que estão para além do econômico, porque "os processos produtivos industriais também introduzem no ambiente novos riscos, de natureza física, química, biológica, mecânica, ergonômica e psíquica, que impactam sobre a saúde dos trabalhadores" (Rigotto, 2008, p. 25) e da população afetada direta e indiretamente por estas indústrias.

$\mathrm{O}$ envolvimento de outros temas na era das descobertas e de exploração dos bens naturais, mais do que uma sofisticação acadêmica, constitui uma questão de sobrevivência da atual geração, assim como das futuras. Há uma necessidade de não negligenciar-se os indícios de que os países tidos como desenvolvidos, pressionados pela sociedade, pelo Estado e pela reforma ecológica, estão exportando riscos para outros países (Rigotto, 2008). A questão que paira é se vale a pena investir nesse modelo de desenvolvimento, que demonstrou total esgotamento no Ocidente e tem desumanizado diferentes comunidades da América Latina, em particular no Brasil. É viável insistirmos nesse modelo acreditando na sustentabilidade?

A situação em que nos encontramos não precisa mais de ações futuras. A hora de agir é agora. Existe unanimidade em muitos autores (Boff, 1999; Fischer, 2001;; Malomalo, 2014) em dizer que diante dos momentos que atravessamos não dá mais para esperar para amanhã, pois os danos, assim como o processo de reparação, podem ser bem maiores que agora.

É tempo de se abraçar o ideal do Fórum Social Mundial: outro mundo é possível. Um mundo em que os seres humanos tenham o bom e o melhor sem destruir a natureza. Para isso, é fundamental a rejeição das utopias conservadoras referidas por Hinkelammert (apud Santos, 1995; 2004). As utopias conservadoras têm como caráter utópico a negação radical de alternativas à realidade atual. "A possibilidade utópica é desacreditada precisamente por ser utópica, idealista, irrealista" (Santos, 2004, p. 9). Essa tem sido a grande razão do triunfo do neoliberalismo. Conseguiu fazer com que muitos deixassem de acreditar em outras possibilidades da existência humana para além das atuais. Consequentemente, todos se veem condenados a aceitar o mundo atual sob o risco de encontrar um pior. Existem poucos crentes de que o futuro pode ser melhor que o presente. Precisamos resgatar as utopias. Compreenda-se utopia como o lugar não existente, o lugar desejável. Como disse René Passet (2002), não podemos deixar que nos digam que este mundo, no qual a lógica financeira por toda parte impõe 
suas leis, que estraga tudo e destrói o sentido das coisas é um mundo necessário. "Um outro mundo é possível; está surgindo ante nossos olhos; está ao alcance de nossas mãos; cabe a nós fazer com que a sua promessa desabroche" (p. 28). O seu alcance é inseparável da luta contra o capitalismo e da mercantilização dos valores humanos (1997). E vale assinalar que, para além de possível, este mundo já está existindo, ou, aliás, sempre existiu, porém, enfrentando muitas resistências por parte do capital. Algumas comunidades de países da América Latina, como Bolívia, Uruguai, Quilombos no Brasil e comunidades "tradicionais" de diversos países africanos, podem servir de exemplos de relações sustentáveis com o planeta (Svampa, 2011; Mansur, 2014; Milanez, 2014; Malomalo, 2014).

\section{O cosmopolitismo subalterno no enfrentamento à acumulação por espoliação}

Os Estados-Governos não têm força para o enfrentamento da lógica do capital. A busca pela conquista e manutenção do poder torna os governantes impotentes a forças capitalistas, o que possibilita que todos se prostrem ante aos interesses das empresas transnacionais. Porém, sabemos quais os ônus que essa rendição causa na humanidade. E não se pode esperar atitude diferente enquanto o sistema de produção capitalista prevalecer. "Um capitalismo humano, social, verdadeiramente democrático e equitativo é mais irreal e utópico que o socialismo" (Wood, 2011, p. 8).

O capitalismo é histórico. Teve seu princípio e pode ter o seu fim. Não é nenhuma fatalidade humana. Já que por via do poder estatal e parlamentar não se consegue superar esse modelo de produção, temos que concordar com Mészáros (2011) que somente um poder extraparlamentar, composto por aqueles que sentem no dia a dia as mazelas do capitalismo, apresenta-se capaz de enfrentá-lo e confrontá-lo. Esses grupos de diferentes oprimidos, articulados, local, nacional, regional e globalmente no enfrentamento às opressões capitalistas, colonialistas e patriarcais, Santos (2010) denomina de cosmopolitas subalternos.

Existem diferentes experiências de enfrentamento às nocivas empresas capitalistas no mundo que podem servir de exemplo para inspirarem as lutas globalmente de forma a derrubar este sistema destruidor. No momento a questão não é se esse modelo de produção vai cair ou não, mas pensar em formas de precaução para que ele não arraste todos ao abismo no momento da sua queda.

Segundo Scotto (2014), na Argentina, a partir dos anos 1990, assistiu-se à forte expansão do modelo minerário, em particular a chamada "megamineração a céu aberto", a comando das grandes empresas transnacionais, à semelhança do que está ocorrendo em Moçambique. Porém, a expansão das atividades foi acompanhada da emergência de conflitos, mobilizações e protestos.

É que a mineração a céu aberto tem provocado problemas ambientais e também "requer um uso desmesurado de recursos, tais como água e energia; ela produz visíveis e profundas mudanças na paisagem e nos territórios. Para retirar os minerais, se remove uma grande quantidade de rochas mediante o uso de toneladas de explosivos" (Scotto, 2014, p. 40). Com o decorrer do tempo, as consequências da mineração foram se visibilizando: "sucessivas rupturas e derrames no mineroduto, causando contaminação das águas, desflorestamento, contaminação do ar por radiação". Perante essas situações, a rejeição à mineração ao céu aberto se fez sentir nas ruas em 2004.

Após grandes mobilizações "No a la mina", a câmara dos vereadores "sancionou uma lei mu- 
nicipal proibindo o uso do cianeto, e revogou a adesão municipal às leis nacionais de investimento e reordenamento mineiro e, junto ao Executivo $\mathrm{Mu}-$ nicipal, convocou a população para um referendum" (Scotto, 2014, p. 42). Os resultados do mesmo, "no dia 23 de março de 2002, indicaram que $81 \%$ da população votou pelo 'No la mina"' (Scotto, 2014, p. 42). Um mês mais tarde, sancionou-se a lei provincial 5.001, que proíbe a atividade de mineração de metálicos na modalidade a céu aberto e a utilização de cianeto nos processos de produção mineira (Scotto, 2014). Essa tendência foi se alastrando em outros territórios por meio de várias estratégias de mobilização popular.

No Peru, Mansur (2014) também mostra várias formas de luta que têm sido desenvolvidas ao longo dos tempos, destacando principalmente casos de criminalização das pessoas que denunciam os efeitos dessas indústrias. A criminalização tem constituído uma arma para alastrar a economia do medo e paralisação dos que acreditam num mundo diferente. De modo semelhante, Milanez (2014) mostra casos de mobilização popular na Costa Rica e vitórias na paralisação dessas atividades.

Apesar das suas nuances, as constituições de Bolívia e Equador são inspiradoras para o mundo que nos é solicitado neste momento. Considerar a terra como sujeito de direitos é algo progressivo, que precisa ser considerado no mundo inteiro.

\section{Conclusão}

O mundo atual, repleto de múltiplas crises, que variam das humanas às ecológicas, solicita a todos nós novas formas de pensar e agir. Os paradigmas da ciência moderna que orientam o pensamento acadêmico não conseguem atender as atuais necessidades. É necessário investimento em outros paradigmas e epistemologias. Os paradigmas subalternos outrora descartados, invalidados e invisibilizados, reduzidos à insignificância, têm muito a oferecer para a contenção das crises atuais. Os países tidos como do Sul global precisam aprender a olhar para o Sul e valorizarem, respeitarem e utilizarem as visões do mundo extraocidentais para direcionarem seus destinos.

Isso passa pela ressignificação da ideia de desenvolvimento. E talvez seja mais coerente pensar em autodeterminação dos povos. Esse pensamento distancia-se da base desenvolvimentista, pois o desenvolvimento é um incontornável aliado do crescimento e, por sua vez, o crescimento é um potente inimigo da preservação da natureza. Para crescer nos moldes do PIB, a natureza vira objeto para melhor apropriação. Nesse momento de crise ecológica com inúmeras consequências humanas, a natureza precisa estar mais próxima de nós. Assim evitamos procurar uma nova terra.

Tudo isso parte da negação de como as coisas estão. O capitalismo destruidor não é irreversível. Ele é construção histórica. Se foi construído, pode ser desconstruído ou até mesmo destruído. Estamos numa disputa. Ou o capitalismo destrói a humanidade ou a humanidade destrói esse sistema parasitário por meio da imposição de alternativas possíveis. Depende de nós, políticos, acadêmicos e cidadãos independentes, principalmente destes últimos, visto que o poder político já vem mostrando impotência perante o capital e alguns acadêmicos se alimentam da falsa consciência. Os que ainda têm alguma luz podem ser potentes aliados dos cidadãos livres, que sentem na pele a destruição de suas vidas. 


\section{Referências}

Bauman, Z. Globalização e consequências humanas. 1. ed. Rio de Janeiro: Zahar, 1999.

Bauman, Z. Vida para consumo: transformação das pessoas em mercadoria. 1. ed. Rio de Janeiro: Zahar, 2008.

Benjamin, W. O capitalismo como religião. 1. ed. São Paulo: Boitempo, 2013.

Bernardo, E. M. Extrativismo em Moçambique: o pensamento abissal na produção e reprodução das injustiças socioambientais e negação do direito à saúde da população. Fortaleza, Dissertação (Mestrado em Saúde Pública) - Universidade Federal do Ceará, 2016.

Bila, I. M. Comunidades abandonadas e enclausuradas em zonas de mineração em Tete. Relatório da Associação Sekelekani: comunicação para o desenvolvimento. 2014.

Boff, L. Saber cuidar: ética do humano, compaixão pela terra. 1. ed. Petrópolis: Vozes, 1999.

Castel-Branco, C. N. Refletindo sobre a acumulação, porosidade e industrialização em contexto da economia extrativa. In: Brito, L. D. et al. Desafios para Moçambique 2013. Maputo: IESE, 2013.

Castel-Branco, C. N.; Cavadias, E. J. O papel dos megaprojetos na estabilidade da carteira fiscal em Moçambique. Apresentação feita no II Seminário Nacional de execução da Política Fiscal e Aduaneira promovido pela Autoridade Tributária, Maputo, 2009.

Fischer, J. Por uma nova concepção da sociedade: uma análise política da globalização. São Paulo: Summus, 2001.

Gonçalves, T. M.; Mendonça, F. A. Impactos, riscos e vulnerabilidade socioambientais da produção de carvão em Criciúmas/SC (Brasil). R. RA'E GA, 14, 55-65, 2007.

Hofmann, K.; Martins, A. S. Descoberta dos recursos naturais em Moçambique: riqueza para poucos ou um meio para sair da pobreza? Moçambique: FES, 2012.

Harvey, D. O novo imperialismo. 8. ed. São Paulo: Loyola, 2014.

Malomalo, B.'I. Filosofia do Ubuntu: valores civilizatórios das ações afirmativas para o desenvolvimento, 2014.
Mansur, M. S. Peru: agricultura X mineração. In: Malerba, J. (Org.). Diferentes formas de dizer não: experiências internacionais de resistências, restrição e proibição ao extrativismo mineral. 1. ed. Rio de Janeiro: Fase, 2014. p. 65-91, 2014.

Marx, K. O capital: crítica da economia política. Livro II: O processo de circulação do capital. 1. ed. São Paulo: Boitempo Editorial, 2014.

Matos, E. A. C.; Medeiros, R. M. V. Acumulação por espoliação: uma reflexão sobre a sua introdução em Moçambique. Revista IdeAS, 7, n. especial, 228-259, 2013.

Mészáros, I. A educação para além do capital. 2. ed. São Paulo: Boitempo, 2008.

Mészáros, I. Para além do capital: rumo a uma teoria da transição. 1. ed. São Paulo: Boitempo, 2011.

Milanez, B. Costa Rica: o verdadeiro ouro do futuro. In: Malerba, J. (Org.). Diferentes formas de dizer não: experiências internacionais de resistências, restrição e proibição ao extrativismo mineral. 1. ed. Rio de Janeiro: Fase, 2014. p. 93-114.

Moraes, M. C. O paradigma educacional emergente. 3. ed. Campinas: Papirus, 1999.

Morin, E. A cabeça bem-feita: repensar a reforma, reformar o pensamento. 14. ed. Rio de Janeiro: Betrand Brasil, 2008.

Morin, E. Ciência com consciência. 15. ed. Rio de Janeiro: Bertrand Brasil, 2013.

Mosca, J.; Selemane, T. El Dorado Tete: os megaprojetos de mineração. Maputo:CIP, 2011.

Passet, R. A ilusão neoliberal. Rio de Janeiro: Record, 2002.

Porto, M. F. et al. Saúde coletiva, território e conflitos ambientais: bases para um enfoque socioambiental critico. Ciência \& Saúde Coletiva, 19(10), 4071-4080, 2014.

Prado Jr., C. Formação do Brasil contemporâneo. São Paulo: Companhia das Letras, 2011.

Ramose, M. B. Globalização e Ubuntu. In: Santos, B. de S.; Meneses, M. P. (Org.). Epistemologias do Sul. São Paulo: Cortez, 2010. 
Relatório de Insustentabilidade da Vale 2015. Disponível em: <https://atingidospelavale.files.wordpress. com/2015/04/relatirio_pdf.pdf $>$.

Rigotto, R. M. Desenvolvimento, ambiente e saúde: implicações da (des)localização industrial. Rio de Janeiro: Fiocruz, 2008.

Santos, B. de S. Toward a New Common Sense: law, science and politics in the paradigmatic transition. Nova Iorque: Routledge, 1995.

Santos, B. de S. Uma concepção multicultural de direitos humanos. Lua Nova, 39, 1997.

Santos, B. de S. O Fórum social mundial: manual de uso. Madison, Dezembro de 2004.

Santos, B. de S. Renovar a teoria crítica e reinventar a emancipação social. São Paulo: Boitempo, 2007.

Santos, B. de S. Um discurso sobre as ciências. 7. ed. São Paulo: Cortez, 2010a.

Santos, B. de S. Para além do pensamento abissal: das linhas globais a uma ecologia de saberes. In: Santos, B. de S.; Meneses, M. P. (Org.). Epistemologias do Sul. São Paulo: Cortez, 2010b.

Santos, B. de S. Moçambique: a maldição da abundância? Visão, 26 de julho de 2012.

Santos, B. de S. Renovar a teoria crítica e reiventar a emancipação social. 1. ed., rev. São Paulo: Boitempo, 2013.
Santos, B. de S.; Meneses, M. P. (Org.). Epistemologias do Sul. São Paulo: Cortez, 2010.

Sartor, D. G. B. A saúde dos trabalhadores das minas de carvão da região carbonífera de Criciúma: uma abordagem qualitativa. Em Debate, 4, 24-41, 2010.

Scotto, G. Argentina: la montaña sigue en pie gracias a su gente. In: Malerba, J. (Org.). Diferentes formas de dizer não: experiências internacionais de resistências, restrição e proibição ao extrativismo mineral. 1. ed. Rio de Janeiro: Fase, 2014, p. 29-52.

Selemane, T. Alguns desafios na indústria extrativa em Moçambique. Maputo: Centro de Integridade Pública de Moçambique (CIP), 2009.

Selemane, T. 50 Questões à volta da mineração em Moçambique: relatório de monitoria das atividades minerais em Moma, Moatize, Manica e Sussundega. Maputo: Centro de Integridade Pública de Moçambique (CIP), 2010.

Svampa, M. Pensar el desarrollo desde América Latina. Texto apresentado no Seminario Latinoamericano "Derechos de la Naturaleza y alternativas al extractivismo", Buenos Aires, Novembro, 2011.

Svampa, M. Pensar el desarrollo desde América Latina. Texto apresentado no Seminario Latinoamericano "Derechos de la Naturaleza y alternativas al extractivismo", Buenos Aires, Novembro, 2011.

Wood, E. M. Democracia contra capitalismo: a renovação do materialismo histórico. 1. ed. São Paulo: Boitempo, 2011. 